\title{
SEÇİLMİŞ OECD ÜLKELERİ İÇİN SAĞLIK HARCAMALARI VE EKONOMİK BÜYÜME: YENİ NESİL PANEL EŞBÜTÜNLEŞME
}

\author{
ANALízi
}

Enver GÜNAY 1

Dilek ATILGAN 2
Received Date (Başvuru Tarihi):

Accepted Date (Kabul Tarihi):

Published Date (Yayın Tarihi):
$16 / 06 / 2020$

$7 / 08 / 2020$

$25 / 09 / 2020$

Çalışmada ilk yazar Sorumlu Yazar (Corresponding Author) rolündedir.

ÖZ

\section{Anahtar Kelimeler:}

Sağllk Harcamaları,

Ekonomik Büyüme,

Panel Eşbütünleşme Analizi

JEL Kodları:

I15,

C23,

010
İ̧sel büyüme teorileriyle birlikte beşerî sermaye kavramı ekonomik büyüme modellerinde giderek önem kazanmıştır. Beşerî sermayenin temel dayanağı eğitim olmakla birlikte sağhlk düzeyi de beşerî sermayeyi besleyen ve gelişimine katkı sağlayan belirleyiciler arasında yer almaktadır. Özellikle sosyoekonomik açıdan gelişmiş toplumsal yapının varlığı, sağlıklı bireyler ile mümkün olmaktadır. Bu bakımdan toplumun ihtiyaçlarını karşılayacak sağllk hizmetlerinin sunulmasl, sağllk hizmetlerine ayrılan kaynak düzeyi ile ilişkilidir. Sağlık hizmetlerine ayrllan kaynakların yeterli düzeyde olması çalışma hayatında verimlilik artışına dolayısıyla ekonomik büyümeye olumlu katkılar sağlayacağı beklenmektedir. Bu bilgiler ışı̆̆ında yapılan çalışmada sağlık harcamaların ekonomik büyüme üzerindeki etkisi ikinci nesil panel ekonometrik yöntemler yardımıyla sınanmıştır. 7 OECD ülkesi için 1985-2018 dönemi baz alınarak yapılan çalışmadan elde edilen sonuçlar; sağllk harcamalarındaki artışın ekonomik büyümeyi pozitif etkilediğini göstermiştir.

$\begin{array}{llll}\text { Keywords: } & \text { Health Expenditure } & \text { Economic Growth } & \text { Panel Cointegration Analysis } \\ \text { JEL Codes: } & \text { I15 } & \text { C23 } & \text { O10 }\end{array}$

${ }^{1}$ Dr. Öğr. Üyesi, Kahramanmaraş Sütçü İmam Üniversitesi İ.İ.B.F, İktisat Bölümü, envergunay@hotmail.com, https://orcid.org/0000-0002-8294-726X

2 YÖK 100/2000 Doktora Öğrencisi, Kahramanmaraş Sütçü İmam Üniversitesi İ.I.B.F, İktisat Bölümü, atlgndilek@hotmail.com, https://orcid.org/0000-0002-3776-558X 


\section{EXTENDED ABSTRACT}

\section{HEALTH EXPENDITURES AND ECONOMIC GROWTH FOR SELECTED OECD COUNTRIES: NEW GENERATION PANEL COINTEGRATION ANALYSIS}

\section{LITERATURE}

The concept of human capital became increasingly more critical among the economic growth models with the development of endogenous growth theories. Although the basic premise of human capital in education, health levels are also among the determinants that nurture and contribute to the development of human capital. Significantly, the existence of a socioeconomically developed social structure is possible with healthy individuals. In this regard, the provision of health services to meet the needs of society is related to the level of resources allocated to health services. It is expected that resources allocated sufficiently to health services will contribute positively to the increase in productivity in business life and thus to economic growth.

When the literature on the current panel studies that discuss the relationship between healthcare expenditures and economic growth is reviewed, it is observed that study periods, variables and methods that are used differ from one study to another. For example, in their study, Dreger and Reimers (2005) found a long-run relation between healthcare expenditures and economic growth for the 21 OECD countries from 1975 to 2001. Mehrara et al. (2012) found a negative relation between healthcare expenditures and economic growth for the 13 MENA countries for the period of 1995-2005. Badri and Badri (2016) study indicates a positive effect of healthcare expenditures on economic growth for the 24 OECD countries for the period of 2006-2013. Agir and Tiras (2018) found a two-way causality between healthcare expenditures and economic growth for a list of 173 countries for the period of 1995-2014. As seen in the examples, the current panel studies that discuss the relationship between healthcare expenditures and economic growth do not yield a conclusion that is valid universally. This study contributes to the literature by employing new panel data analysis techniques even though many studies discuss the relationship between healthcare expenditures and economic growth.

\section{DESIGN AND METHOD}

This study investigates the effect of healthcare expenditures on economic growth for the selected 7 OECD countries (Australia, Canada, Finland, Germany, Turkey, UK and USA), considering the availability of data. In this study, the empirical relation between healthcare expenditures and economic growth was analyzed by the current techniques in the panel data literature in light of the data obtained from the World Bank and OECD. Gauss 19 and Stata 14.2 econometric package programs were used for forecasts.

In the economic growth and healthcare expenditure model, the homogeneity of the coefficient of the independent variable is tested by slope homogeneity test, developed by Pesaran and Yamagata (2008). To determine the cross-section dependency in the model, Breusch and Pagan (1980) Lagrange Multiplier Test, CD and CDLM tests (Pesaran (2004)), and LMadj test, developed by Pesaran et al. (2008) were used. After these analyses, PANICCA test which is one of the $2^{\text {nd }}$ generation panel unit root tests that was developed by Reese \&Westerlund (2016), based on standard factor modelling, and considers cross-section dependency was implemented. The LM test that was developed by Westerlund and Edgerton (2007) was used to investigate whether there is a long-run relationship between health and economic growth. Augmented Mean Group Estimator that was developed by Eberhardt and Teal (2010) was used to analyze long-run coefficients.

\section{FINDINGS AND DISCUSSION}

The findings in this study support the internal growth models and show that a $1 \%$ increase in healthcare expenditures causes a $0.3 \%$ increase in economic growth. According to the results based on each country, the expenditures on health services in Australia, Canada, Turkey, UK and USA increases economic growth. These results support the studies on this topic in the literature. 


\section{CONCLUSION, RECOMMENDATION AND LIMITATIONS}

In the light of the results, it should be emphasized that the effect of healthcare expenditures on economic growth, for sustainable growth performance, does not only depend on financial resources allocated to healthcare services but also healthcare policies that are chosen. In this regard, the strength of the causality relation between healthcare expenditures and economic growth varies according to health systems, healthcare infrastructures and social structures of countries. To be able to increase the effect of healthcare expenditures on growth, healthcare policies must be improved. Also, the policies that support justice should be adapted in the use of healthcare services; all segments of society should be able to benefit from healthcare services by making quality healthcare services available even to the poor. 


\section{GİRIŞ}

Sağlık hakkı, yaşama hakkı ile doğrudan ilişkili olan ve yaşama hakkıyla birlikte doğuştan kazanılan en temel insan haklarından birisidir. Sağlık hizmetleri bakımından gelişme kaydeden toplumların, öğrenme becerilerinin gelişmesi ve üretkenliklerinin artması beklenir. Sağlık harcamalarına ayrılan kaynaklar büyüdükçe beşerî sermayenin gelişeceği ve bunun refah düzeylerine olumlu katkılar sağlayacağı beklenmektedir. Bu nedenle ekonomideki pozitif ilerlemenin sosyal refaha daha fazla yansıması ve sağlıklı bir toplum yetiştirilmesi için sağlık harcamalarına ayrılan payın sağlık ihtiyaçlarını karşılayacak düzeyde olması gerekmektedir. Sağlık harcamaları ve büyüme ilişkisini inceleyen ilgili literatür, sağlık harcamalarındaki artışın bireyin ve toplumun beşerî gelişmişliğini yükselterek ekonomik büyümeye olumlu yönde katkı sağladığını ortaya koymaktadır (Narayan vd., 2010; Wang 2011; Cebeci ve Ay 2016; Badri ve Badri 2016; Fazaeli 2016; Ağır ve Tıraş, 2018).

Ekonomik büyüme ve ekonomik büyümeyi besleyen kaynaklar bilimin gündeminden hiç düşmeyen konulardır. Bu anlamda klasik büyüme modelleri sorgulamakta ve modern büyüme teorileri kurulmaktadır. Solow Modeli'nin eksiklikleri ve ekonomik büyüme incelemeleri, büyümenin nasıl meydana geldiği ve dolayısıyla büyümeyi etkileyen politikaların neler olduğunu açıklamaya yönelik yeni teorilerin ortaya çıkmasına neden olmuştur (Taban, 2016:141). 1980'li yılların sonlarına doğru ilk olarak Amerikalı iktisatçı Paul M. Romer (1986) ile ardından Robert E. Lucas (1988) ve Barro (1990)'nun çalışmaları büyümeye yönelik yeni teorilerin oluşmasına zemin hazırlamıştır. Bu bakımdan içsel (yeni) büyüme teorileri, büyüme için asıl öneme sahip olan yapının, beşerî sermaye olduğunu belirtmektedir (Kibritçioğlu, 1998, 223). Yeni yaklaşımlar büyüme dinamiklerinin merkezine beşerî sermayeyi yerleştirdikçe; sosyal hizmetler, beşerî sermayenin gelişmesine yönelik yatırımlar, eğitim, çevre gibi sosyal konular, kapsamlı ve derinlikli sağlık hizmetleri ile daha fazla sağlık harcamaları ekonomik gelişmenin öne çıkan dinamikleri olmaktadır.

Beşerî sermaye, çalışan bireylerin bilgi ve beceri kapsamında üretkenliklerini ortaya koyabilecekleri tüm nitelikleri ifade etmekle beraber eğitim düzeyi, sağlık ve 
beslenme değişkenleri beşerî sermayeyi etkileyen önemli unsurlar olarak görülmektedir (Taban, 2016: 151 ve Göv, vd., 2019, 782). Beşerî sermaye, eğitim düzeyi ve beslenmenin yanında işgücü stokunu ve verimliliğinin kalitesini yükselterek gelir düzeyini artıran bir unsur olarak ele alınmaktadır (Woodhall, 1987, 21). Güncel büyüme modellerinde; sağlık hizmetlerine yapılan yatırımların işgücünün verimliliğini arttırdığı, bununla birlikte sağlık harcamalarındaki artışın yaşam süresini, beklentisini ve kalitesini artırarak ekonomik büyümeye olumlu katkılar sağladığı savunulmaktadır (Ay ve Yardımc1, 2006: 491).

Ülkelerin siyasal ve ekonomik sistemlerinin özelliği ile kültürel ve sosyal yapılarındaki farklılıklar, sağlık hizmetlerine ayrılan payların ülkeden ülkeye değişiklik göstermesine neden olmaktadır. Bu kapsamda evrensel geçerliliğe sahip olan görüş, ülkelerin ekonomik gelişmişlik seviyeleri ile sağlık düzeyi arasında anlamlı bir ilişkinin varlığı kanısıdır. Ekonomik gelişmişlik seviyesi belli bir düzeyde olan toplumlarda sağlık için ayrılan kaynak miktarının yükseldiği fakat uyguladıkları sistemler açısından birbirlerinden ayrıştığı ifade edilmektedir (Ağır ve Tıraş, 2018: 1559).

Bu çalışmada, veri ulaşılabilirliği dikkate alınarak, 1985-2018 dönemi için seçilmiş 7 OECD ülkesi (Avustralya, Kanada, Finlandiya, Almanya, Türkiye İngiltere ve $A B D)$ kapsamında, sağlık harcamalarının ekonomik büyüme üzerine etkisi, panel veri literatüründe geliştirilen güncel teknikler yardımıyla incelenmiştir. İlgili literatür incelendiğinde, sağlık harcamaları ile ekonomik büyüme ilişkisini konu edinen birçok çalışma yapılmasına rağmen bu çalışma kullanılan yeni panel ekonometrik yöntemler bakımından diğer çalışmalardan ayrılmaktadır.

Araştırmada literatür taraması ortaya konulduktan sonra, çalışmanın diğger aşamasında ikinci nesil panel veri analizi teknikleri kullanılarak örneklem ülke grubu için söz konusu dönem aralığında sağlık harcamalarının ekonomik büyüme üzerine etkisi incelenecektir. 


\section{LITTERATÜR İNCELEMESI}

Sağlık göstergeleri ve ekonomik büyüme arasındaki ilişkiyi ele alan güncel panel çalışmalarına ilişkin literatür incelendiğinde; çalışmaların incelenen dönem, kullanılan değişken ve yöntemlere göre farklılıklar gösterdiği görülmektedir.

Tablo 1. Sağlık Göstergeleri ve Ekonomik Büyüme İlişkisini Ele Alan Güncel Panel Çalışmalar

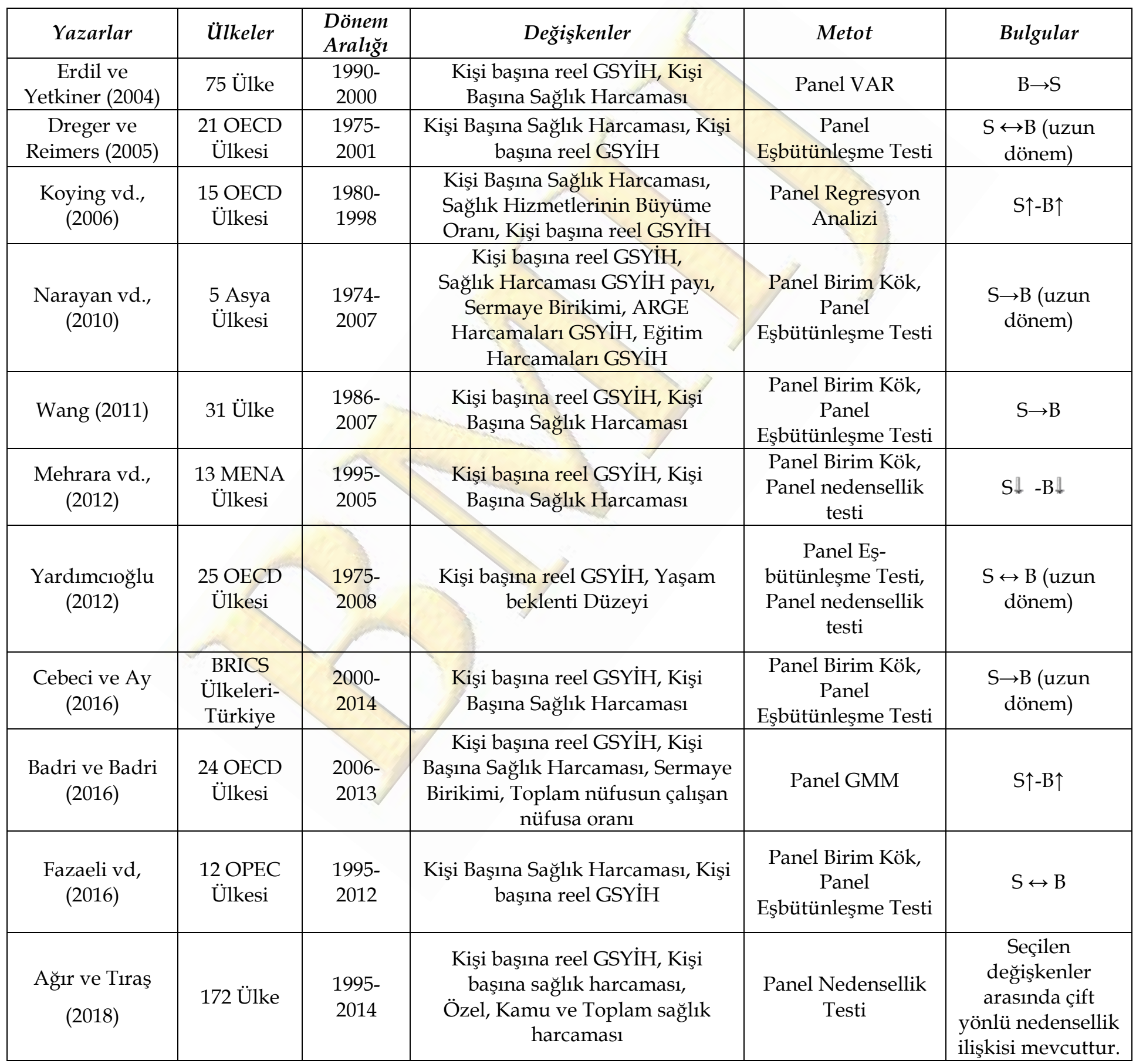

Not: Nedensellik sütununda yer alan $S \rightarrow B$, sağlık harcamalarından büyümeye, $B \rightarrow S$, büyümeden sağlık harcamalarına doğru tek yönlü nedensellik ilişkinin olduğunu; $S \leftrightarrow B$, çift yönlü nedensellik ilişkisini ve $S \uparrow$-B $\uparrow$ değişkenler arasında pozitif ve $S \downarrow$-B

$\downarrow$ değişkenler arasında negatif ilişkinin olduğunu göstermektedir. 
Tablo 1'de derlenen; sağlık göstergeleri ve ekonomik büyüme ilişkisini ele alan güncel panel çalışmalar; bize evrensel geçerliliğe sahip bir sonuçtan bahsetmenin mümkün olmadığını göstermekte bu bakımdan sağlık harcamaları ile ekonomik büyüme ilişkisini konu edinen birçok çalışma yapılmasına rağmen bu çalışma kullanılan yeni panel veri analizi teknikleri bakımından diğer çalışmalardan ayrılarak literatüre katkı sağlamaktadır.

\section{VERİ SETİ VE METODOLOJİ}

\subsection{VERİ SETİ}

Sağlık göstergeleri ve ekonomik büyüme arasındaki ilişkinin analizi kapsamında değişkenlerin tanımlanmasına ait bilgiler Tablo 2'de gösterilmektedir. Değişkenleri simgeleyen göstergelerin önündeki LN ön ek, değişkenlerin logaritmik formlarının kullanıldığını ifade etmektedir. Gauss 19 ve Stata 14.2 ekonometri paket programları kullanılarak tahminler yapılmıştır.

Tablo 2. Analizde Kullanılan Değişkenlerin Tanımı

\begin{tabular}{|l|l|c|}
\hline Değişkenler & \multicolumn{1}{|c|}{ Tanım } & Kaynak \\
\hline LNGDP & Log kişi başına gelir (ABD \$) & Dünya Bankası \\
\hline LNSH & $\begin{array}{l}\text { Log kişi başına sağlık harcaması } \\
\text { (ABD \$) }\end{array}$ & OECD. Stat \\
\hline
\end{tabular}

$\mathrm{Bu}$ değişkenlerle kurulan ekonometrik model ise denklem 1'de gösterilmektedir.

$$
\begin{aligned}
& L_{N G D P}=a_{i t}+\beta_{1 i t} L_{N S H}+\varepsilon_{i t} \\
& (i=1 \ldots, 7) \text { ve }(t=1985 \ldots, 2018)
\end{aligned}
$$

Modele 7 OECD ülkesi ${ }^{3}$ çercevesinde incelenmiştir. Analizde i; kesit boyutunu ve t; zaman boyutunu belirtmektedir.

\subsection{METODOLOJİ}

$\mathrm{Bu}$ çalışmada, veri ulaşılabilirliği dikkate alınarak, seçilmiş 7 OECD ülke veri setleri ile ekonometrik tahminler yapılmıştır. Panel veri analizi, N sayıda birim (firma,

\footnotetext{
3 (Avustralya, Kanada, Finlandiya, Almanya, Türkiye İngiltere ve ABD)
} 
sektör, ülke) ve buna karşılık gelen T sayıda gözlemden oluşarak grup ve zaman etkilerini görebilmeye olanak sağlayan bir ekonometrik analizdir (Tatoğlu, 2013: 9).

Sağlık harcamaları ve ekonomik büyüme arasındaki eş bütünleşme ilişkisini tahmin edebilmek için öncelikle ön testlerin yapılması gerekmektedir. Bu ön testlerden biri, yatay kesit bağımlılığının olup olmadığı durumudur. Değişkenlerde ve modelde yatay kesit bağımlılı̆̆ının olup olmadığının belirlenmesi için Tablo 3'te yer alan yatay kesit bağımlılık (Cross Section Dependency) testleri yapılmaktadır. Testin boş hipotezi " $H_{0}$ : Yatay kesit bağımlılı̆̆ı yoktur" şeklindedir. Yatay kesit bağımlılığının olması bir ülke ekonomisinde meydana gelen bir şokun diğer ülke ekonomilerini etkileme durumunu ifade etmektedir. Kesitler arası bağımlılığın varlığı modelde ikinci nesil birim kök testlerin uygulanmasına olanak sağlamaktadır (Nazlığlu, 2010: 142). Bu bakımdan Reese\&Westerlund (2016) PANICCA testi, ortak faktör modellemesine dayalı ve kesitler arası bağımlılı̆̆a duyarlı güncel ikinci nesil panel birim kök testidir. PANICCA testi, serilerin sadece seviyede durağan olup olmadıklarını göstermektedir. Farklarında ise birim kök içerip içermediklerine ilişkin bilgi barındırmamaktadır (Ağır ve Türkmen, 2020: 5). Test "Seriler birim kök içermektedir"; boş hipotezine karşılık, "Seriler dură̆andır" diyen alternatif hipotezini sinamaktadır (Reese ve Westerlund 2016: 971).

Ön testlerden bir diğeri ise eğim katsayılarının homojen mi yoksa heterojen mi olduğunun durumudur. Ekonomik büyüme ve sağlık harcamaları modelinde, homojenlik testi Pesaran ve Yamagata (2008) Eğim Katsayısı Homojenliği ile belirlenmiştir. Homojenite testinde, "Eğim katsayıları homojendir" boş hipotezine karşılık, "Ĕğim katsayıları heterojendir" diyen alternatif hipotezini sinamaktadır.

Sağlık harcamaları ve ekonomik büyüme arasında uzun dönem ilişkinin varlığ1 McCoskey ve Kao (1998)'nun Lagrange çarpanı (LM) testi ile incelenmiştir. LM testi bootstrap özelliğini kullanarak kesitler arasında ve içerisinde korelasyona izin vermektedir (Özcan ve Arı, 2014: 47). Testin boş hipotezi "eşbütünleşme vardır" şeklindedir. Değişkenlerin uzun dönem katsayıları ise Augmented Mean Group (AMG) tahmincisi ile analiz edilmektedir. 


\section{AMPİİK SONUÇLAR}

Panel birim kök testlerinden hangisinin uygulanacağını karar vermek için ilk olarak kesitler arası bağımlılığının olup olmadığı, Tablo 3'te yer alan testler yardımıyla irdelenecektir. Tablo 3, seçilmiş 7 OECD ülkesine ait yatay kesit testi sonuçları gösterilmektedir.

Tablo 3. Yatay Kesit Bağımlılı̆̆ı Test Sonuçları

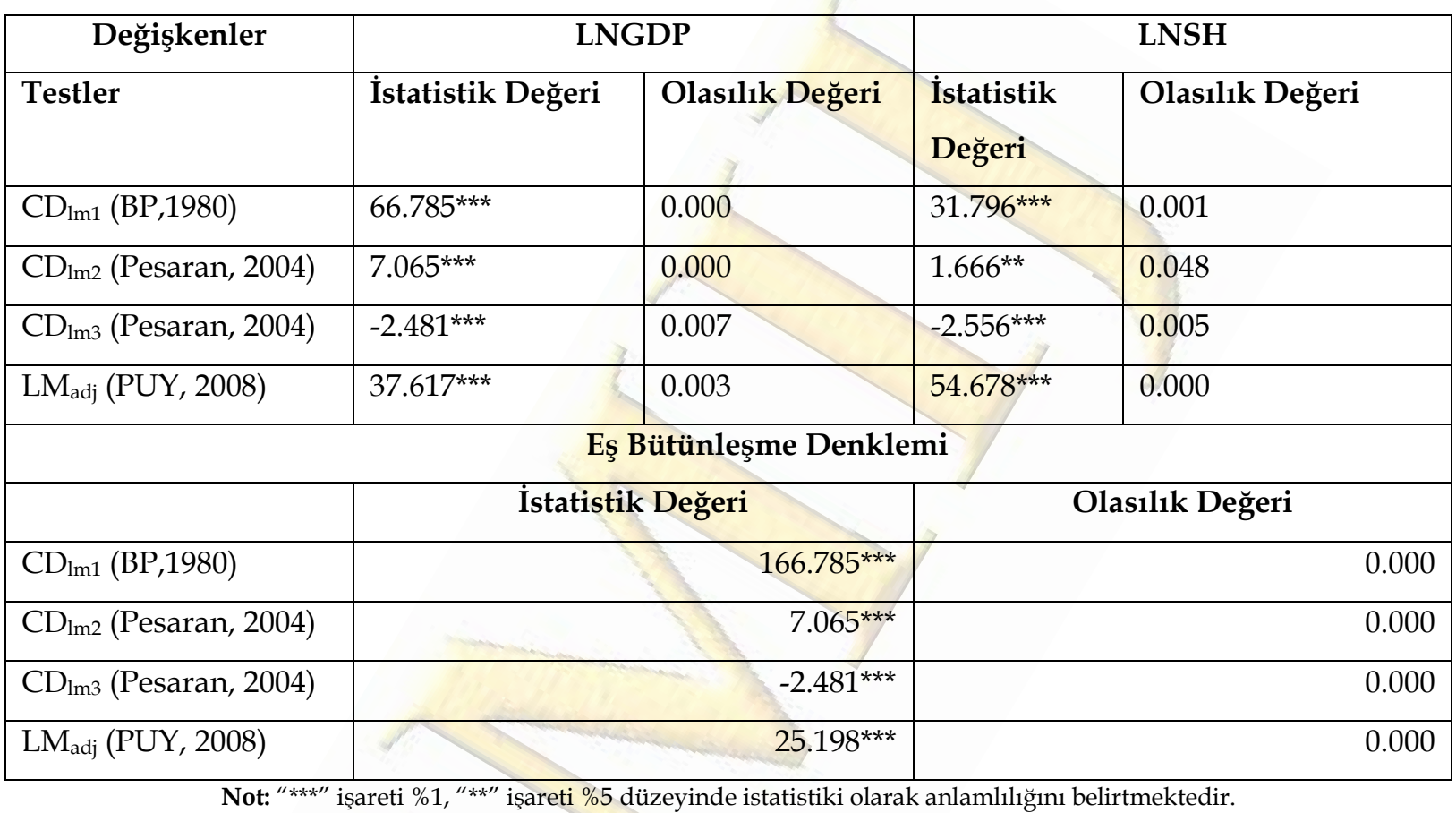

Yatay kesit bağımlılı̆̆ı test sonuçları \%1 ve \%5 anlamlılık düzeyinde reddedilmekte hem serilerde hem de eş bütünleşme denkleminde kesitler arası bağımlılık olduğu tespit edilmiştir. Bulgular, bir ülke ekonomisinde meydana gelen şokun, diğer ülke ekonomilerini de etkileyeceğini ifade etmektedir.

Yatay kesit bağımlılığın varlığı, ikinci nesil panel birim kök ve ikinci nesil eşbütünleşme testlerinin uygulanmasını gerektirmektedir (Özcan, 2015: 7). Reese\&Westerlund (2016) tarafından geliştirilen PANICCA testi en güncel ikinci nesil panel birim kök testidir. PANICCA testi sonuçları Tablo 4 'te gösterilmektedir. 
Tablo 4. Reese \&Westerlund (2016) Test Sonuçları

\begin{tabular}{|c|c|c|c|c|c|}
\hline \multirow{3}{*}{\multicolumn{2}{|c|}{ Birim Kök Testi }} & \multicolumn{2}{|c|}{ LNGDP } & \multicolumn{2}{|c|}{ LNSH } \\
\hline & & \multicolumn{4}{|c|}{ Düzey } \\
\hline & & Sabit Terimli & Sabit ve Trendli & Sabit Terimli & Sabit ve Trendli \\
\hline \multirow{3}{*}{ PANICCA } & $\mathrm{Pa}$ & $-0.246(0.403)$ & $4.650 \quad(1.000)$ & $-0.301(0.382)$ & $8.576(1.000)$ \\
\hline & $\mathrm{Pb}$ & $-0.254(0.400)$ & $21.737(1.000)$ & $-0.233(0.408)$ & $45.589(1.000)$ \\
\hline & PMSB & $-0.279(0.610)$ & $67.599(1.000)$ & $-0.790 \quad(0.215)$ & $88.691(1.000)$ \\
\hline
\end{tabular}

Test sonuçları serilerin seviyede birim kök içerdiğini göstermektedir. Serilerin seviyede birim kök içermesi, ülke ekonomilerine gelen bir şokun etkisini hemen kaybetmeyerek şokların kalıcılığını ifade etmektedir. Bu bağlamda PANICCA test sonuçları kapsamında serilerin düzeyde durağan olmaması, koşulu eşbütünleşme testlerinin uygulanabilmesine olanak sağlanmaktadır (Kar vd; 2019: 43).

Eş-bütünleşme testinden önce modelin eş-bütünleşme katsayısının homojen olup olmadığı belirlenmelidir. Tablo 5 'de eğim homojenliği test sonuçları gösterilmektedir.

Tablo 5. Eğim Homojenliği Test Sonuçları

\begin{tabular}{|l|r|r|}
\hline Testler & İstatistik Değeri & Olasılık Değeri \\
\hline Delta Tilde & $3.863^{*}$ & 0.000 \\
\hline Delta Tilde & \\
\hline \multicolumn{2}{|c|}{$4.046^{*}$} & 0.000 \\
\hline \multicolumn{2}{|c|}{ Not: “*” işareti \%1, düzeyinde istatistiki olarak anlamlılı̆̆ın belirtmektedir. }
\end{tabular}

Modelin homojen olduğu üzerine kurulu eğim homojenliği test sonuçları \%1 anlamlılık düzeyinde reddedilmekte ve katsayının heterojen olduğu sonucuna ulaşılmaktadır. Modellerde katsayıların heterojen olması, ülke gruplarının ekonomik yapılarının birbirinden bağımsız olduğunu göstermektedir (Kar, vd., 2019: 42).

Eş-bütünleşme testinin tespiti LM testi ile incelenmiştir. Tablo 6' da Eşbütünleşme test sonuçları gösterilmiştir.

Tablo 6. Eş-bütünleşme Test Sonuçları

\begin{tabular}{|c|c|c|c|}
\hline & LM İstatistiği & Asimtotik p-değeri & Bootstrap p-değeri \\
\hline LMN+ & 0.562 & 0.816 & 0.287 \\
\hline
\end{tabular}

Not: Bootstrap olasılık değerleri 1000 tekrarlı dağılımdan elde edilmiştir. Sabitli model kullanılmıştır. 
Analiz sonuçlarına göre kesitler arası bağımlılığın var olması bootstrap olasılık değerinin kullanılmasını ifade etmektedir bu değer kapsamında "eş-bütünleşme vardır" şeklinde oluşturulan boş hipotez reddedilememektedir. Boş hipotezin kabul edilmesi, ekonomik büyüme ve sağlık harcamaları arasında uzun dönemli bir ilişkinin mevcut olduğunu belirtmektedir.

Eşbütünleşme ilişkisi belirlendikten sonra yatay kesit bağımlılı̆̆ına ve katsayılarda heterojenite duyarlı Eberhardt ve Teal (2010) tarafından geliştirilen AMG (Augmented Mean Group) yöntemi kullanılmıştır. Tablo 7, seçilmiş 7 OECD ülkesi panel eş-bütünleşme katsayı tahmin sonuçlarına yer verilmektedir.

Tablo 7. Seçilmiş OECD Ülkelerinde Panel Eş-Bütünleşme Katsayı Tahmin Sonuçları (AMG)

\begin{tabular}{|l|r|r|r|}
\hline & \multicolumn{3}{|c|}{ LNGDP=f(LNSH) } \\
\hline & \multicolumn{1}{|c|}{ Katsayı } & Std. Hata & \multicolumn{1}{c|}{ p-değeri } \\
\hline AMG & $0.333^{* * *}$ & 0.071 & 0.000 \\
\hline Ülke Sonuçları \\
\hline Avustralya & $0.317^{* * *}$ & 0.096 & 0.001 \\
\hline Kanada & $0.362^{* * *}$ & 0.089 & 0.000 \\
\hline Finlandiya & 0.119 & 0.082 & 0.151 \\
\hline Almanya & 0.162 & 0.100 & 0.106 \\
\hline Türkiye & $0.323^{* * *}$ & 0.054 & 0.000 \\
\hline Ingiltere & $0.343^{* * *}$ & 0.090 & 0.000 \\
\hline ABD & $0.701^{* * *}$ & 0.024 & \\
\hline \multicolumn{1}{|r|}{ Not: “***” \%1 düzeyinde istatistiksel olarak anlamlılığ1 ifade etmektedir. }
\end{tabular}

AMG eş-bütünleşme tahminci sonuçlarına göre seçilmiş 7 OECD ülkeleri kapsamında, panel sonucunun istatistiksel olarak anlamlı olduğu görülmektedir. Bu bakımdan, tahminde kullanılan seçilmiş 7 OECD ülkesi için sağlık harcamalarındaki \%1'lik bir artışın, ekonomik büyümeyi \%0,3 oranında artırdığı ifade edilmektedir. Sonuçlar ülke bazında ele alındığında; Avustralya, Kanada, Türkiye İngiltere ve $\mathrm{ABD}^{\prime}$ de pozitif ve istatistiksel olarak anlamlı bir ilişkinin varlığı söz konusudur. 


\section{SONUÇ ve ÖNERİLER}

İçsel (yeni) büyüme teorileri kapsamında, beşerî sermayenin önemli belirleyicilerinden biri olan sağlık harcamalarının, ekonomik büyümeye olumlu katkılar sağladığı kabul edilmektedir. Ekonomik kalkınmanın sağlanmasında önemli role sahip olan sağlık harcamaları, ülke ekonomilerinin gelişmişlik düzeylerine göre farklılık göstermekle birlikte sağlık harcamalarına ayrılan payın artması bebek ve çocuk ölümlerinin azalmasına, doğum ve ölüm oranlarının düşmesine, ortalama ömrün yükselmesine ve bireylerin daha sağlıklı beslenme imkânına sahip olmasını sağlayarak ekonomik büyümeyi pozitif etkilediği görülmektedir.

Bu çalışmada, veri ulaşılabilirliği dikkate alınarak, 1985-2018 dönemi için seçilmiş 7 OECD ülkesi (Avustralya, Kanada, Finlandiya, Almanya, Türkiye İngiltere ve $A B D)$ kapsamında, sağlık harcamalarının ekonomik büyüme üzerine etkisi, panel veri literatüründe geliştirilen güncel tekniklerin yardımıyla incelenmiştir. Elde edilen bulgular, içsel büyüme teorilerini desteklemekte ve seçilmiş 7 OECD ülkesinde, sağlık harcamalarındaki \%1'lik bir artışın, ekonomik büyümeyi \%0,3 oranında artırdığı yönündedir. Araştırma sonuçları ülkeler bazında yorumlandığında; Avustralya, Kanada, Türkiye İngiltere ve ABD'de sağlık hizmetlerine yapılan harcamaların, ekonomik büyümeyi artırdığı sonucu ortaya çıkmaktadır. Bulgular ilgili literatürde daha önce yapılan çalışmaları destekler niteliktedir.

Elde edilen bilgiler 1şığında sağlık harcamalarının ekonomik büyüme üzerindeki önemi vurgulanırken ülkelerin sürdürülebilir büyüme performansı yakalayabilmelerinin sağlık hizmetlerine ayrılan finansman kaynakları kadar, uyguladıkları sağlık politikaları ile ilişkili olduğu belirtilmelidir. Bu bağlamda sağlık harcamalarının ekonomik büyüme ile nedensellik ilişkisinin şiddeti, ülkelerin sağlık sistemine, sağlık altyapı durumuna, sosyal yapılarına göre farklılık gösterdiği ifade edilmektedir. Sağlık harcamalarının büyüme üzerindeki etkisini artırmak için sağlık politikalarının iyileştirilmesi gerekmektedir. Bunun yanı sıra ülkelerde sağlık hizmetleri kullanımında hakkaniyetin sağlanmasına yönelik politikalar uygulanmalı ve sağlık hizmetleri kalitesine yoksul kesiminde ulaşabilmesinin yolu açılarak sağlık hizmetlerinden toplumların tüm kesimlerinin yararlanması sağlanmalıdır. 


\section{KAYNAKÇA}

Ağır, H. ve Tıraş, H., (2018). “OECD Ülkelerinde Sağlık Harcamaları ve Ekonomik Büyüme İlişkisi: Panel Nedensellik Analizleri” , Siyaset, Ekonomi ve Yönetim Araştırmaları Dergisi, 6 (4): 13-29.

Ağır, H., ve Türkmen, S., (2020). “Ekonomik Büyümeye Etkisi Bakımından Doğal Kaynaklar: Dinamik Panel Veri Analizi", Gaziantep Üniversitesi, Araştırma Makalesi, 19 (3): 1-11.

Ay, A. Yardımcı, P., (2006). “Türkiye'de Fiziksel ve Beşerî Sermaye Birikimi İle Ekonomik Büyüme Arasındaki İlişkilerin Var Modeli ile Analizi (1950-2000)", Bilgi, Ekonomi ve Yönetim Kongresi, 155: 491-502.

Badri, A. K. ve Badri, S. K., (2016), "Health Spending and Economic Growth in Selected OECD Countries", American Journal of Clinical Neurology and Neurosurgery, 2 (1): 5-9.

Baltagi, B.H. (2008), Econometric Analysis of Panel Data, Fourth Edition, West Sussex: John Wiley \& Sons.

Barro, R. J., (1990). “Government Spending in a Simple Model Of Endogenous Growth", Journal of Political Economy, 98 (5): 103-125.

Breusch T.S. and Pagan, A.R.. (1980), "A Lagrange multiplier test and its applications to model specification in econometrics", Review of Economic Studies, 47 (1): 239-253.

Cebeci, E. Ahmet, A., (2016), “The Effects Of Health Expenditures On Economic Growth: A Panel Regression Analysis on BRICS Countries and Turkey", Dumlupınar Üniversitesi Sosyal Bilimler Dergisi, Özel Sayı, ss. 91-102.

Dreger, C., ve Reimers, H. E., (2005). “Health Care Expenditures in OECD Countries: A Panel Unit Root and Cointegration Analysis", Iza Discussion Paper, No. 1469.

Eberhardt, M. ve Teal, F., (2010), “Aggregation versus Heterogeneity in Cross-Country Growth Empirics", Centre for the Study of African Economies, Department of Economics, No: 17692, 1-37.

Erdil, E. ve Yetkiner, I. H. (2004). "A Panel Data Approach For İncome- Health Causality", The Economics of Health Reforms, (Ed. J.N. Yfantopoulus), 38, 701-724. https://www2.uni-hamburg. de/Wiss/FB/15/Sustainability/yetkiner/ papers/FNU47.pdf Erişim T: 04. 04.2020.

Fazaeli, A. A., Ghaderi, H., Salehi, M., ve Fazaeli, A. R., (2016), “Health Care Expenditure and GDP in Oil Exporting Countries: Evidence from OPEC Data, 1995-2012", Global Journal of Health Science, 8 (2): 93-98.

Göv, A., Orhan, E, B., ve Köstekçi, A., (2019), “Sağlık Harcamaları İle Ekonomik Büyüme ve İnsani Gelişme Endeksi İlişkisi: OECD Ülkeleri İçin Ekonometrik Bir Analiz”, Journal of Academic Value Studies, 5 (5): 781-790. 
Kar, M. Ağır, H. ve Türkmen, S., (2019), “Seçilmiş Gelişmekte Olan Ülkelerde Elektrik Tüketiminin Ekonomik Büyümeye Etkisinin Panel Ekonometrik Analizi", Uluslararası Ekonomik Araştırmalar Dergisi, 5 (3): 38-48.

Kibritçioğlu, A. (1998). İktisadi Büyümenin Belirleyicileri ve Yeni Büyüme Modellerinde Beşerî Sermayenin Yeri, Ankara Üniversitesi SBF Dergisi, 53 (1): 207-230.

Koying, C. ve Young-Hsiang, Y. (2006). “Economic Growth, Human Capital İnvestment, and Health Expenditure: a Study of OECD Countries", Hitotsubashi Journal Of Economics, 47 (1): 1-16.

Lucas, E. R., (1988). “On The Mechanics of Economic Development”, Journal of Monetary Economics, $22(1): 3-42$.

Mehrara, M., Fazaeli, A.A., Fazaeli, A.A. ve Fazaeli, A.R., (2012). “The Relationship between Health Expenditure and Economic Growth in Middle East \& North Africa (MENA) Countries" , International Journal Business Managment Economic Research, 3 (1): 425-428.

Narayan, S., Narayan, P. K. ve Mishra, S. (2010). “Investigating the Relationship Between Health and Economic Growth: Empirical Evidence From a Panel of 5 Asian Countries", Journal of Asian Economics, 21: 401-411.

Nazlığlu, Ş., (2010), “Makro İktisat Politikalarının Tarım Sektörü Üzerindeki Etkileri: Gelişmiş Ve Gelişmekte Olan Ülkeler Için Bir Karşılaştırma”. Yayınlanmamış Doktora Tezi, Erciyes Üniversitesi Sosyal Bilimler Enstitüsü, Kayseri.

Özcan, B., (2015), “Çke Hipotezi Yükselen Piyasa Ekonomileri İçin Geçerli Mi? Panel Veri Analizi”, Doğuş Üniversitesi Dergisi, 16 (1): 1-14.

Özcan, B., ve Arı, A. (2014), “Araştırma-Geliştirme Harcamaları ve Ekonomik Büyüme İlişkisi: Panel Veri Analizi”, Maliye Dergisi, 166 (1): 39-55.

Pesaran, H., (2004), “General Diagnostic Tests for Cross Section Dependence in Panels". Cambridge: University of Cambridge Working Paper.

Pesaran, M. H., (2007), "A Simple Panel Unit Root Test in the Presence of Cross-Section Dependence". Journal of Applied Econometrics, 22: 265-312.

Pesaran, M. H., Ullah, A., ve Yamagata, T., (2008), “A Bias-adjusted LM Test of Error Cross-section Independence". Econometrics Journal, 11: 105-127.

Reese, S. and Westerlund, J. (2016), "Panicca: Panic on Cross-Section Averages", Journal of Applied Econometrics, 31 (6): 961-981.

Romer, P. M., (1986). “Increasing Returns and Long Run Growth”, Journal of Political Economy, 94 (5): 1002-1037.

Taban, S., (2016), “ İktisadi Büyüme Kavram ve Modeller”, Ekin yayınevi, Bursa, 183. 
Tatoğlu, Y, F., 2013. “Panel Veri Ekonometrisi Stata Uygulamaları, Beta Yayınlar, İstanbul, 306s.

Wang, K., (2011). "Health Care Expenditure and Economic Growth: Quantile Panel-Type Analysis”, Economic Modelling, 28: 1536-1549.

Westerlund, J., ve Edgerton, D. L. (2007), “A Panel Bootstrap Cointegration Test”, Economics Letters, 97: 185-190.

Woodhall, M., (1987). “Human capital concepts, Edited: G. Psacharopoulos, Economics of Education Research and Studies", Advanges in Education, Pergamon Pres, The World Bank, Washington, DC, USA.

Yardımcıŏ̆lu, F., (2012). “OECD Ülkelerinde Sağlık ve Ekonomik Büyüme İlişkisinin Ekonometrik İncelenmesi”, Eskişehir Osmangazi Üniversitesi Sosyal Bilimler Dergisi, 13 (2): 27-47. 